\title{
Challenging Issues of Tribal Education in India
}

\author{
Dr. KabitaKumariSahu \\ Lecturer in Economics, North Orissa University Baripada, Odisha
}

\begin{abstract}
The objective of the paper is to analyse the status of tribal education with literacy rate, gross enrolment ratio, dropout rates and Gender Parity Index in India. The analysis is based on secondary data of Census of India, 2011. The percentage of literacy of tribes was only 8.54 per cent in 1961 which has increased to 63.1 per cent in 2011. The gross enrolment ratio is higher in class I to V which is 137.2 for ST boys and 136.7 for ST girls.The Gender Parity Index for ST children is almost same as all categories of children except for class XI to XII.

Key Words: Drop out, Education, Enrolment, Literacy, Tribes
\end{abstract}

\section{Introduction}

India is a home to a large variety of indigenous people. The Scheduled Tribe population represents one of the most economically impoverished and marginalized groups in India. With a population of more than 10.2 crores, India has the single largest tribal population in the world. This constitutes 8.6 per cent of the total population of the country (Census of India, 2011).Education is one of the primary agents of transformation towards development. Education is in fact, an input not only for economic development of tribes but also for inner strength of the tribal communities which helps them in meeting the new challenges of life.It is an activity, or a series of activities, or a process which may either improve the immediate living conditions or increase the potential for future living. It is the single most important means by which individuals and society can improve personal endowments, build capacity levels, overcome barriers, and expand opportunities for a sustained improvement in their well-being. Professor AmartyaSen recently emphasized education as an important parameter for any inclusive growth in an economy. So, education is an important avenue for upgrading the economic and social conditions of the Scheduled Tribes. Education is in fact, an input not only for economic development of tribes but also for inner strength of the tribal communities which helps them in meeting the new challenges of life. Literacy and educational attainment are powerful indicators of social and economic development among the backward groups in India. Currently, the tribes lag behind not only the general population but also the Scheduled Caste population in literacy and education. This disparity is even more marked among Scheduled Tribe women, who have the lowest literacy rates in the country (Maharatna, 2005). The male-female gap in literacy and educational attainment among the scheduled tribes is significant. Education, especially in its elementary form, is considered of utmost importance to the tribals because it's crucial for total development of tribal communities and is particularly helpful to build confidence among the tribes to deal with outsiders on equal terms. Despite the sincere and concerted efforts by the government for the overall development of the scheduled tribes, they are still far behind in almost all the standard parameters of development. They are not able to participate in the process of development, as they are not aware of most of the progrmmes and policies made for their upliftment. This is mainly due to the high incidence of illiteracy and very low level of education among the tribal people. Hence, the educational status of the scheduled tribes and the role of governance in this direction are highly essential. It is well known that the educational background of tribes is very discouraging as compared to the rest of the population. So, education is an important avenue for upgrading the economic and social conditions of the Scheduled Tribes. In this context, the objective of this paper is to analyse the trend of literacy rate, gross enrolment ratio, dropout rates and Gender Parity Index of tribal education in India.

\section{Literature Review}

There exists a substantial amount of literature on the condition of tribal education in India. A brief review is worthwhile in order to highlight what has already been done in the field.In a study on tribes of Andhra Pradesh, K. Sujatha (1994) contends that the perspective adopted for educational development of tribal communities fails to adequately address the specific disadvantages characterizing the tribal population. She found that one of the major constraints of tribal education at the planning level is the adoption of a dual system of administration. Rani, M (2000) observed in her study that due to the language barrier the tribal children are unable to establish communication link with the teacher and thus leading to the termination of their education in some point or the other. Vaidyanathan and Nair, (2001) suggested that teacher motivationcontributes more to teaching - learning process than teacher competence.Sujatha, K. (2002) revealed that though education was not 
a critical demand among Scheduled Tribes, government policy focused on education as the main avenue by which to integrate them into 'mainstream' society. Jha\&Jhingran, D. (2002) have strongly advocated the use of the mother tongue or home language as medium of instruction in early stages of education. This assumes greater significance in the context of education of tribal children because their mother tongue is often quite distinct from the prominent languages in the state or regional languages and it is desirable to have a local teacher from the same tribal community. The Praitichi Committee Report (2002) identifies cost of schooling, lack of motivation of teachers, lack of inspection, and the increasing dependence on private tutoring to be the main hurdles in the path of education for tribal children.

Gautam, V. (2004) in his articlefound thathigh "dropout" rates among tribal children He analysed that due to wrong medium of instruction, the appointment of non-tribal teachers in tribal areas and communication gap between the teachers and tribal children are the causes of high dropout rates in tribal schools. Maharatna, A. (2005) the key challenge does not concern how tribes can be brought within the folds of mainstream society and culture, but how a more voluntary and mutual interaction between tribes and mainstream society can be developed. Lal, M. (2005) found that among all school dropouts, Adivasis and Dalits form the biggest group. Further, the largest group amongst them is girls. Education, thus for the weaker sections of the society needs to become the panacea and an inclusive growth strategy for their economic and social up-liftment. Education has special significance for the SCs and STs who are facing a new situation in the development process. Nair, P. (2007) has given importance on non-formal education in tribal areas particularly to reach out to the hardest-toreach group of children in remote areas. NFEs therefore target children who are drop-outs from the formal system of education. This non-formal method provides room for innovations and injects flexibility to a rigid system in terms of organization, teaching method, content, target group of learners and evaluation procedures.Sedwal, M. and Kamat, S. (2008) focused on issues related to Scheduled Castes and Scheduled Tribes - groups which are recognised for affirmative action within the Constitution of India. Abdulraheem, A. (2011) explained that education as an important parameter for any inclusive growth in an economy and the policies have to focus on inclusive rather than divisive growth strategies.

\section{Status of Tribal Population in India}

The tribal population constitutes a majority in the northeastern states of Mizoram andLakshadweep(94.4 per cent), Meghalaya (86.1per cent), and Nagaland (86.5per cent). The states with no Scheduled tribe groups are Punjab, Chandigarh, Haryana, Delhi and Pondicherry.India has total tribal population of 10.43 crores (Table-1) which is 8.6 per cent (Table-2) of total population of India as per 2011 census.

Table-1 ScheduledTribepopulationand decadalchangebyresidence in 2011

\begin{tabular}{|c|c|c|c|c|c|c|}
\hline & \multicolumn{2}{|c|}{ Scheduled Tribe population2011 } & \multicolumn{3}{c|}{ Decadal change2001-2011 } \\
\hline & Total & Rural & Urban & Total & Rural & Urban \\
\hline India & $104,281,034$ & $93,819,162$ & $10,461,872$ & 23.7 & 21.3 & 49.7 \\
\hline
\end{tabular}

Source - Census of India, 2011

During 2001 and 2011, the decadal change in the scheduled tribe urban population is 23.7 per cent where as it is 49.7 per cent in urban area and 21.3 per cent in rural area. The urban India has only 2.8 per cent ST population but Rural India has 11.3 per cent ST population. (Table-2)

Table-2 Percentageof ScheduledTribesto totalpopulation in India: 2001-2011

\begin{tabular}{|c|c|c|c|c|c|c|}
\hline \multirow{2}{*}{} & \multicolumn{3}{|l|}{ Percentageof ScheduledTribes2001 } & \multicolumn{3}{l|}{ Percentageof ScheduledTribes 2011} \\
\cline { 2 - 7 } & Total & Rural & Urban & Total & Rural & Urban \\
\hline India & 8.2 & 10.4 & 2.4 & 8.6 & 11.3 & 2.8 \\
\hline
\end{tabular}

Source - Census of India, 2011

\section{Literacy Trends of tribes in India}

Literacy is an important indicator of development among tribal groups. The trend of literacy of tribes in India from 1961 to 2011 is shown in table -3 . The percentage of literacy of tribes was only 8.54 per cent in 1961 which has increased to 63.1 per cent in 2011. But female literacy of tribes is only 54.4 per cent compared to male literacy of 71.7 per cent. During the post-Independence period, the Indian government implemented legislation and allocated funds to facilitate access to enrollment in primary education (grades I-V) in India. As a result, both literacy rates and gross enrollment ratios of boys and girls across the general population have increased substantially during the past 50 years. 
Table- 3 Literacy Trends of Scheduled Tribes in India from 1961 to 2011( in Percent)

\begin{tabular}{|c|c|c|c|}
\hline Year & Male & female & Total \\
\hline 1961 & 13.83 & 3.16 & 8.54 \\
\hline 1971 & 17.63 & 4.85 & 11.39 \\
\hline 1981 & 24.52 & 8.05 & 16.35 \\
\hline 1991 & 40.65 & 18.19 & 29.60 \\
\hline 2001 & 59.17 & 34.76 & 47.10 \\
\hline 2011 & 71.70 & 54.4 & 63.1 \\
\hline
\end{tabular}

Source: National Commission for SCs \& STs, Fifth Report \& Census, 2011

The literacy rate among ST boys is 71.7 per cent and among girls is 63.1 per cent. So there is significant improvement in ST literacy from 1961 (8.54 per cent) to 2011 (63.1 per cent).

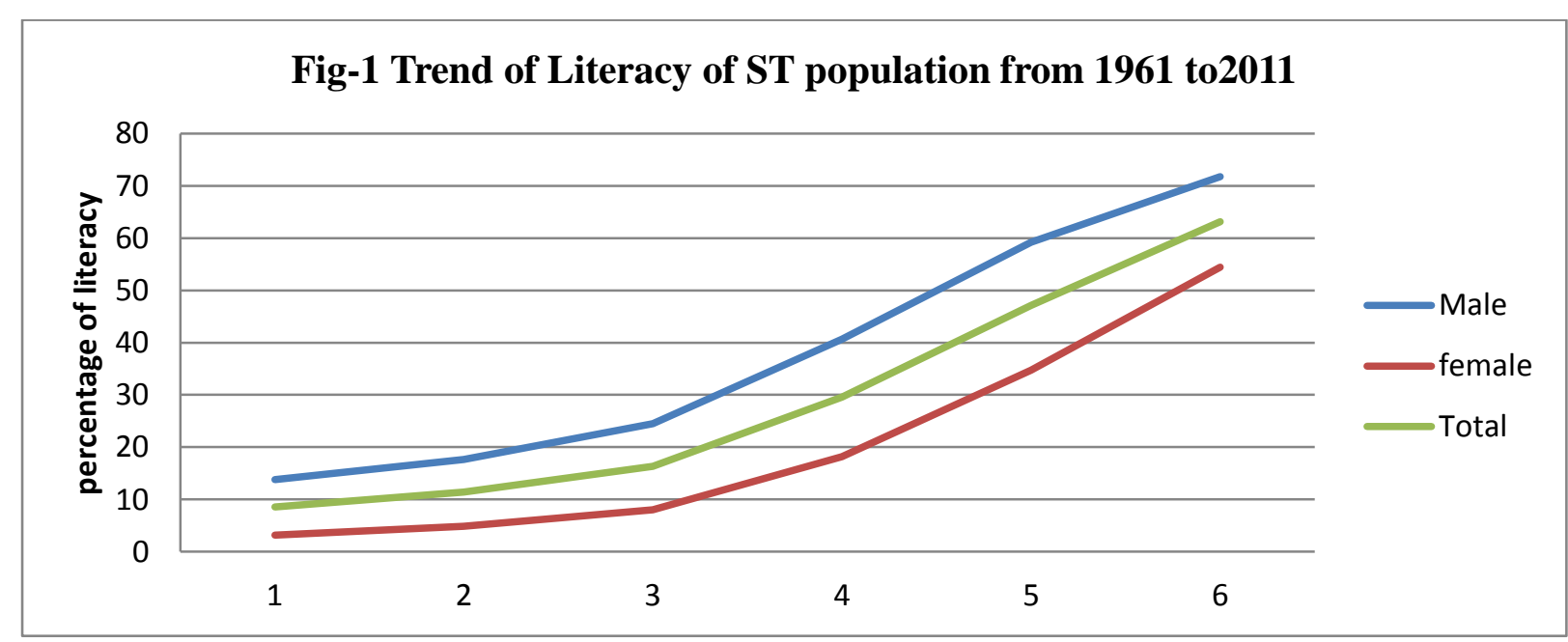

\section{Enrolment Ratio of ST students}

Gross enrolment ratio of ST boys is more than ST girls in all classes. The gross enrolment ratio is higher in class I to V which is 137.2 for ST boys and 136.7 for ST girls but it is only 90.7 and 87 in class VI to VIII. It implies that the tribal enrolment declines significantly in higher class.

Table-4 Gross Enrolment Ratio (GER)
\begin{tabular}{|ll|l|l|}
\hline Classes & ST (Boys) & ST (Girls) \\
\hline Classes I - V (6 - 10 Years) & 137.2 & 136.7 \\
\hline Classes VI - VIII $\quad(11-13$ Years) & 90.7 & 87 \\
\hline Classes IX - X (14 - 15 Years) & 57.1 & 49.1 \\
\hline Classes XI - XII $\quad(16-17$ Years) & 32.7 & 24.8 \\
\hline Classes I - XII (6 - 17 Years) & 96.8 & 92.8 \\
\hline
\end{tabular}

Source-Statistics of School Children, 2010-2011

Gender Parity Index reflects the enrolment of girls in school in comparison to boys. The index for ST children is almost same as all categories of children except for class XI to XII. (Table-5)

Table-5 Gender Parity Index in Education

\begin{tabular}{|c|c|c|}
\hline Class & ST & All \\
\hline Classes I - V & 1.00 & 1.01 \\
\hline Classes VI - VIII & 0.96 & 0.95 \\
\hline Classes IX - X & 0.86 & 0.88 \\
\hline Classes XI - XII & 0.76 & 0.86 \\
\hline Classes IX - XII & 0.82 & 0.87 \\
\hline Classes I - XII & 0.96 & 0.96 \\
\hline
\end{tabular}

Source- Statistics of School Children, 2010-2011

The dropout rateof ST children is higheras compared to all children in India. (Table-6).

Table-6 Drop out rate among ST boys and girls

\begin{tabular}{|l|l|l|l|l|}
\hline Class & ST( Boys) & All( Boys) & ST( Girls) & All(Girls) \\
\hline Classes I - V & 37.2 & 28.7 & 33.9 & 25.1 \\
\hline Classes I - VIII & 54.7 & 40.3 & 55.4 & \\
\hline Classes I - X & 70.6 & 50.4 & 71.3 & 41.0 \\
\hline
\end{tabular}




\section{Problems of Tribal Education}

There are many critical issues and problems in the field of tribal education. They are as follows:

I. Medium of language - Language is one of the important constraints of tribal children which prevents them access to education.

II. The Location of the Village - The physical barriers creates a hindrance for the children of a tribal village to attend the school in a neighboring village.

III. Economic Condition - The economic condition of tribal people is so poor that they do not desire to spare their children or their labour power and allow them to attend schools.

IV. Attitude of the parents - As education does not yield any immediate economic return, the tribal parents prefer to engage their children in remunerative employment which supplements the family income.

V. Teacher Related Problems -In the remote tribal areas the teacher absenteeism is a regular phenomenon and this affects largely the quality of education.

VI. Lack ofProper monitoring- Proper monitoringis hindered by poor coordination between the Tribal Welfare Department and School Education Department.

Government Policies and Programmes for Tribal Education

Starting from the First Five Year Plan Period1 (1951-1956) the government is steadily allocating financial resources for the purpose of tribal development. Towards, the end of the plan (1954), 43 Special Multipurpose Tribal Development Projects (MTDPs) were created. During the Third Five Year Plan Period (1961-1966), the government of India adopted the strategy of converting areas with more than 66 per cent tribal concentration into Tribal Development Blocks (TBDs). By the end of Fourth Five Year Plan (1969-1974), the number of TBDs in the country rose to 504. Additionally, in 1972 the Tribal Sub-Plan Strategy (TSP) was implemented by the Ministry of Education and Social Welfare. TSP was based on twin objectives of socio-economic development and protection against exploitation. It was generally implemented in the areas where the Scheduled Tribe population was more than 50 per cent of the total population.

The PESA (The Panchayats Extension to Scheduled Areas) Act, 1996 in fact, has made it mandatory for the States having scheduled areas to make specific provisions for giving wide-ranging powers to the tribes on the matters relating to decision-making and development of their community. A centrally-sponsored government scheme of ashram schools exclusively for ST children from elementary to higher secondary levels was initiated in the 1970s. But the poor quality of education in ashram schools, however, has undermined confidence in education as a vehicle for social mobility.

The JanshalaProgramme is a collaborative effort of the Government of India (GOI) and five UN Agencies UNDP, UNICEF, UNESCO, ILO and UNFPA - a community based primary education programme, aims to make primary education more accessible and effective, especially for girls and children in deprived communities, marginalised groups, Scheduled Caste/Scheduled Tribes/minorities, children with specific needs.

\section{Suggestions}

Some suggestions for improvement of tribal education are as follows-

a) Literacy campaign - Proper awareness campaign should be organized to create the awareness about the importance of education. Extensive literacy campaign in the tribal dominated districts may be undertaken on a priority basis to literate the tribal.

b) Attitude of the tribal parents - The attitude of the tribal parents toward education should be improved through proper counseling and guidance.

c) Relevant study materials in local languages - All study materials should be supplied in local languages of tribes.

d) Appointment of Local teachers and female teachers - It is suggested to appoint more tribal teachers and female teachers in the tribal areas. The ecological, cultural, psychological characteristics of tribal children should be considered carefully by the teachers in tribal areas.

e) Stipends and various scholarships - Since higher education among the tribes is less, special ST scholarships should be provided to the tribal students perusing higher education, particularly in medical, engineering, and other vocational streams.

f) Residential schools - More residential schools should be established in each states and districts and extended up to PG level in tribal areas.

g) Social security- Social security of students, especially of adolescent girls is of great concern in residential schools.

h) Proper Monitoring - Higher level officials should check the functioning of schools frequently relating to the teaching methods, working hours, and attendance registers. 


\section{Conclusion}

Education is the key to tribal development. Tribal children have very low levels of participation. Though the development of the tribes is taking place in India, but the pace of development has been rather slow. If govt. will not take some drastic steps for the development of tribal education, the status of education among tribes will be a story of distress, despair and death. Hence time has come to think it seriously about tribal education and inclusive growth. So, there is an urgent need for various govt. interventions, planners and policy makers to address this problem and allocate more funds in the central and state budgets for tribal education. Easy access and more opportunities should be provided to the tribal children in order to bring them to the mainstream of economic development.

\section{References}

[1] Abdulraheem, A. (2011) Education for the Economically and Socially Disadvantaged Groups in India: An Assessment Economic Affairs Vol. 56 No. 2 June 2011 (Page 233-242)

[2] Jha, J., Jhingran, D. (2002), Elementary Education for the Poorest and Other Deprived Groups, Centre for Policy Research. New Delhi.

[3] Lal, M. (2005), Education-The Inclusive Growth Strategy for the economically and socially disadvantaged in the Society

[4] Nair, P.( 2007), "Whose Public Action? Analyzing Inter-sectoral Collaboration for Service Delivery: Identification of Programmes for Study in India."International Development Department, Economic and Social Research Council.February.

[5] Sedwal, M. \&Sangeeta, K.(2008) Education and Social Equity with special focus on Scheduled Castes and Scheduled Tribes in Elementary Education,NUEPA, New Delhi

[6] Sujatha, K. (2002) Education among Scheduled Tribes. In Govinda, R. (ed.), India Education Report: A Profile of Basic Education New Delhi: Oxford University Press. 